\title{
Paediatric Rheumatology: Foster H. and Brogan P. A. (eds)
}

\author{
Published by Oxford University Press, United Kingdom, ISBN: 978-0-19-959263-0, \\ First Edition: 2012
}

Received: 8 January 2013 / Accepted: 8 January 2013 / Published online: 9 February 2013

(C) Dr. K C Chaudhuri Foundation 2013

Paediatric Rheumatology is a relatively unexplored branch in India, where the subject is not taught at the undergraduate or postgraduate level. The books available in this subject are few and dauntingly thick! How does a post graduate student or a pediatrician with an interest in this subject sharpen his skills and increase his knowledge?

The New Oxford Specialist Handbook in Paediatric Rheumatology edited by Foster and Brogan and published in 2012 is one such resource. This handbook is a 465 page manual that is easy to carry. All the chapters have been contributed by members of the BSPAR (British Society of Paediatric and Adolescent Rheumatology). The book has been divided into ten sections that deal with clinical skills and assessment, common clinical problems, Juvenile idiopathic arthritis (JIA), connective tissue diseases and vasculitis, through till infections and the role of the multidisciplinary team assessment.

Each section is brief and to the point with key features given in bullet points. The disease specific chapters deal with outcome measures and goals to be reached during the vertical follow up of the patients. The sections deal with clinical features, investigations, management, outcomes and prognosis of important diseases.

The one content that the book lacks is giving the clinical based approach to symptoms such as fever with rashes, monoarthritis, polyarthritis, multisystem disease approach, when to suspect vasculitis or auto inflammatory syndromes. The chapters also have useful charts for therapeutic pathways which would have been much better in larger fonts and available as "pull outs"

In summary, a good concise ready reckoner for the subject. A must have for the pediatrician with an interest in rheumatology.

S. Sawhney $(\bowtie)$

Department of Pediatric Rheumatology, Institute of Child Health, Sir Ganga Ram Hospital,

New Delhi 110060, India

e-mail: drsujatasawhney@gmail.com 